\title{
A Integração dos Imigrantes de Leste em Portugal. Contributos para a sua análise ${ }^{l}$
}

\author{
Alexandra Castro $^{2}$ \\ Sofia Delgado Marques ${ }^{3}$
}

\begin{abstract}
$\mathrm{R}$
Lesumo: Neste artigo apresenta-se parte das conclusões de uma investigação realizada entre 2005 e 2007 no Centro de Estudos Territoriais, com base em três estudos de caso. Uma parte muito importante da informação recolhida e aqui analisada consiste em entrevistas realizadas a 29 imigrantes da Moldávia, Roménia, Rússia e Ucrânia. Entre outras, este estudo propunha-se analisar a questão dos processos de integração dos imigrantes de Leste em Portugal. Esta análise foi feita através de uma abordagem biográfica e histórica dos processos de desintegração vividos pelos imigrantes e suas famílias nas sociedades de origem, a tratar noutro local, bem como da análise dos percursos migratórios na sociedade portuguesa. A este nível, procurou-se dar conta dos constrangimentos que, do lado da sociedade de acolhimento, se colocam aos imigrantes, e das características do próprio fluxo, das estratégias, recursos mobilizados e, de forma genérica, nas formas de reconstrução da participação dos imigrantes na sociedade de acolhimento. Finalmente, pretendeu-se considerar a natureza segmentada dos processos de integração, analisando as características dos contextos territoriais em que se fixam os imigrantes.
\end{abstract}

Palavras-chave: Imigrantes da Europa de Leste; Integração.

\section{Considerações iniciais: processos de integração dos imigrantes}

As questões da integraçãoconstituem uma das áreas de estudo das migrações mais abrangentes no seu tratamento. Se não cabe no espaço deste artigo apresentar uma discussão relativa aos entendimentos que esta noção tem vindo a ter, convém contudo apresentar de forma sucinta o referencial teórico-analítico que serviu de enquadramento à investigação sobre os processos de integração dos imigrantes da Moldávia, Roménia, Ucrânia e Rússia.

Como primeiro ponto, referencia-se a discussão de integração aos contributos que Pires (2003) deu para a reconceptualização desta noção no âmbito dos processos migratórios, bem como a um entendimento da participação social ancorado no conceito de cidadania.

Seguindo a definição de Pires (2003) relativamente ao significado de integração admite-se que esta diz respeito aos modos de incorporação dos actores em novos quadros de interacção em consequência de episódios de mudança social e de deslocamentos intra-sistema de ordem (ciclos geracionais ou mobilidade social), ou inter-sistemas de ordem (migrações) (Pires, 2003: 4). Trata-se pois de perceber como são resolvidos os problemas de reconstrução pelos actores da sua integração na ordem interactiva na sequência de situações críticas. As estratégias, recursos mobilizados, avaliações discursivas sobre o próprio percurso migratório e projectos migratórios foram os elementos de

\footnotetext{
1 Este artigo apresenta parte dos resultados do projecto de investigaçāo "Entre o rural e o urbano: estratégias de integraçāo de famílias de imigrantes da Europa de Leste" que decorreu no Centro de Estudos Territoriais, entre 2005 e 2007, com o financiamento da Fundação para a Ciência e a Tecnologia (PIQS/SOC/50046/2003). A equipa coordenada por Madalena Matos foi composta, para além das autoras do artigo, por Joana Afonso e Maria José Lobo Antunes. As dinâmicas que conduziram à decisão de migrar destes imigrantes, dimensão indispensável na abordagem dos processos de integração, foi já objecto de publicação no número 15 desta revista (Antunes, 2008).

2 Investigadora do Centro de Estudos Territoriais. castro.alexandra@gmail.com

Técnica superior do Instituto da Segurança Social, I.P. Ana.s.marques@seg-social.pt
} 
observação que se teve em conta para reconstituir as modalidades dessa reconstrução da participação. Importa ainda dar conta das soluções que a sociedade de destino encontrou para acolher os imigrantes, de uma maneira geral, e este grupo em particular, sobretudo nas vertentes que mais imediatamente se impõem ao seu quotidiano.

Posta nestes termos, procurou-se mais do que encontrar uma posição no quadro de uma visão dicotómica em que estaria de um lado, a integração e do outro, a não integração, identificar modalidades de integração, bem como as dimensões e variáveis pertinentes para traduzir tais modalidades e para compreender os factores que conduziram à emergência da forma de participação encontrada pelos imigrantes.

Naquilo que diz respeito às modalidades, pretendeu-se ter em conta posições de síntese entre modelos assimilacionistas e modelos estruturais (Heisler, 1992), como é a de Pires, mas que emerge também noutros modelos (Machado, 1999; Portes, 1999). Neles se propõe uma abordagem que acolhe, enquanto ideais-tipo, visões do processo de integração tradicionalmente opostas: etnicização/ /etnicidade, contraste, por um lado, continuidade, assimilação, por outro.

No que diz respeito às dimensões e variáveis relevantes para apurar a natureza dos processos de integração e o seu sentido de interpretação reteve-se por um lado, traços de caracterização do grupo de imigrantes em análise (Machado, 1999) e variáveis que quer relativamente aos fluxos, quer relativamente às sociedades de acolhimento (Pires; 2003) dão conta dos factores potenciadores de formas de participação de sentidos diversos.

Relativamente ao retrato do grupo em termos dos seus traços, procurou-se considerar não só diferenças culturais nomeadamente ao nível da língua e da proficiência no seu uso, do sentido das sociabilidades - mais ou menos étnicas -, mas também da importância de diferenças ao nível mais estrutural, traduzidas na posição de classe, no perfil demográfico e nas características da fixação residencial. Procurou-se ainda dar conta de outras dimensões importantes para discutir a modalidade de integração dos imigrantes moldavos, romenos, russos e ucranianos na sociedade portuguesa, susceptíveis de permitir uma leitura mais dinâmica da questão. Tais dimensões estão relacionadas quer com características do fluxo migratório (competências e recursos, dimensão, informalidade na sua organização e importância das redes, configuração do projecto migratório), quer com as dinâmicas das sociedades de acolhimento, designadamente, as orientações dos estados nacionais relativamente a políticas de identidade e à regulação do acesso aos direitos e as reacções sociais às migrações ${ }^{4}$ (Pires, 2003).

Dar conta da variabilidade das formas de integração não implica abandonar a ideia de que os processos de integração podem ser menos bem-sucedidos, naturalizando diferenciais no acesso dos que vivem numa determinada sociedade aos direitos que são consensualmente aceites por essa mesma sociedade. Deste ponto de vista, importa não perder de vista a noção de cidadania no entendimento das formas como se configura a participação dos imigrantes. De resto, a noção de exclusão não está ausente das propostas teóricas de compreensão das modalidades de integração a que se fez referência mais directa, surgindo tendencialmente mais associada a umas que a outras.

Importa ainda fazer duas últimas notas. A primeira prende-se com a possibilidade de analisar a integração de um contingente com uma história de permanência relativamente recente. Alguns autores preferem equacionar as questões da integração apenas na segunda geração (Portes, 1999), outros como Machado (1999) a partir do reagrupamento familiar. Esta segunda hipótese foi aquela que pareceu razoável seguir nesta investigação, partindo da noção de ciclo migratório explorada por Felice Dassetto (1990) ${ }^{5}$. Interessou, sobretudo, reter desta noção a ideia de que de meros actores económicos,

\footnotetext{
Segundo esta perspectiva, estariam associadas a modalidades de integração mais próximas da etnicização a importância das redes informais na organização dos fluxos; a estruturação dos espaços de acolhimento dos imigrantes enquanto espaços étnicos à chegada; a posse de baixas competências formais e recursos instrumentais; aspectos relacionados com o ciclo migratório, como as fases iniciais da integração dos imigrantes, bem como a transitoriedade na definição dos projectos migratórios; chegadas contínuas e de fluxos numerosos. Do lado das dinâmicas das sociedades de acolhimento, a etnicização associa-se a políticas restritivas às entradas, sobretudo se houver hiatos entre estas restrições e o desenvolvimento real do fluxo; a imposição de barreiras no acesso dos estrangeiros aos direitos de cidadania, particularmente aos direitos sociais e laborais; recepções sociais caracterizadas pela discriminação e estigmatização decorrentes dos processos de discriminação estrutural sofridos pelos imigrantes.

5 Desenvolvida a partir do "ciclo de relações sociais" de Park, nos anos 20, dá conta das várias fases por que passa o processo de fixação dos imigrantes na sociedade de acolhimento, atribuindo à fase de reagrupamento familiar ou do casamento já em contexto de imigração, a segunda fase do ciclo, a estabilização, em que a aquisição progressiva de regras codificadas e não escritas da vida colectiva ganha saliência, e na qual se pode utilizar o termo de aculturação.
} 
os imigrantes passam a ter uma presença nas sociedades de acolhimento que se estende às várias esferas sociais, ao interagirem com um leque mais alargado de instituições. Colocam-se nesta fase, já questões no relacionamento com a forma como está organizada a educação, com as instituições de saúde, com a Segurança Social, que se distinguem daquelas que estavam associadas à mera relação salarial. Também os consumos e os investimentos começam a desviar-se da sociedade de origem. É assim, definitivamente de processos de reconstrução e alargamento das esferas da participação social, de reestruturação da relação com o tempo e com o espaço e de reorientação para as sociedades de acolhimento desta reestruturação que se trata nesta investigação. Nesta medida, parece legítimo equacionar a natureza dos processos de integração dos imigrantes nas sociedades de acolhimento.

A segunda nota diz respeito à necessidade de considerar os diferenciais numa mesma sociedade ao abordar a integração dos imigrantes, fazendo-se uso da noção de integração segmentada (Zhou, 1997). Partindo desta noção, esta investigação procurou entender a importância dos factores contextuais associados às diferenças territoriais na configuração das modalidades de integração.

\section{Desenho da pesquisa e enquadramento metodológico}

A investigação de que aqui se apresentam parte dos resultados, decorreu entre Setembro de 2005 e Março de 2007, tendo sido acompanhados vinte e nove entrevistados, homens e mulheres, de quatro nacionalidades: moldavos, romenos, russos e ucranianos em três contextos diferentes, Lisboa, Peniche e Alentejo. No desenho desta pesquisa, partiu-se da constatação de os imigrantes provenientes da Europa de Leste se fixarem em todo o território nacional, ao contrário da concentração nas zonas metropolitanas registada para os imigrantes de outras origens. Tanto as estatísticas disponíveis ${ }^{6}$ como alguns estudos sobre esta população ${ }^{7}$ apontavam para este facto, o que levou a definir como objectivo central a necessidade de compreender a relação entre contextos de fixação e dinâmicas de integração destes imigrantes, em função de uma análise comparada de casos relativos a diferentes contextos territoriais de estabelecimento dos imigrantes.

Num primeiro momento, interessava compreender a pertinência e validade da distinção entre territórios e, nomeadamente, entre territórios rurais e urbanos para, num segundo momento, podermos fundamentar a selecção dos casos a integrar na análise. Da revisão da literatura sobre esta questão ${ }^{8}$ pode concluir-se, desde logo, que a simples dicotomia rural/urbano não é a que melhor caracteriza a organização socioeconómica do espaço, nem a que melhor permite distinguir territórios. Mais do que uma oposição entre territórios urbanos e territórios rurais, tivemos em conta, na selecção dos casos, dois critérios que permitem marcar diferenças e desigualdades espaciais: (a) o que opõe zonas de fraca densidade socioeconómica a zonas de forte capacidade institucional e material (Reis, 1999: 33) e (b) o que distingue as áreas rurais segundo a sua proximidade física, mas também funcional e socioeconómica, aos principais centros urbanos (Ferrão, 2000: 47). Se cada vez é mais contestável a separação dos territórios em áreas rurais e urbanas existem, no entanto, especificidades que importa realçar ao nível dos modos de trabalho, de habitat e de vida em situações locais específicas. O mesmo é dizer que nenhum dos critérios utilizados a nível macro para distinguir áreas urbanas e rurais é suficiente, pois é preciso ter em consideração critérios intrínsecos à área em análise para determinar o estatuto de espaço considerado.

A escolha de Lisboa como estudo de caso prendeu-se com duas ordens de razões: a primeira é de ordem teórico-metodológica. Para discutir os efeitos dos contextos na integração não poderia deixar de se contemplar o contexto urbano e metropolitano. As questões da adaptação ou assimilação colocam-se pela primeira vez, na literatura das ciências sociais, associadas às dinâmicas de crescimento e transformações das cidades; é por relação às

\footnotetext{
${ }^{6}$ A dispersão geográfica é evidente se se der atenção ao peso relativo deste grupo em distritos como o de Beja, Braga, Castelo Branco, Coimbra, Évora, Leiria, Santarém, Vila Real, Viseu ou a Madeira. Em todos estes distritos estes imigrantes são aqueles com maior peso relativo face ao total de pessoas em situação regular e o mais baixo peso relativo no distrito de Lisboa.

7 Baganha et al. 2004, Fonseca et al. 2004, Perista 2005, Pires, 2003; Malheiros e Vala, 2004.

${ }^{8}$ Cf. Entre outros Mingione e Pugliese, 1987; Guerra, 1991; Janvie, 1993; Remy, 1998, Ferrão, 2000; Reis, 2001 ; Castro e Marques, 2005.
} 
cidades que se define o sentimento do estrangeiro, mas também da liberdade da vida mental proporcionada pelo anonimato da vida nestes contextos. A segunda prende-se com a importância que tem a capital portuguesa na concentração de imigrantes e, não obstante a maior dispersão da população proveniente dos países do leste europeu, também deste grupo ${ }^{9}$.

A escolha de Peniche como estudo de caso permite ilustrar uma situação intermédia entre o rural e o urbano: por um lado, a sua densidade socioeconómica e a proximidade relativa a alguns dos principais centros urbanos do país aproxima-o de territórios de tipo urbano; por outro lado, o peso do sector primário ainda é relevante: cerca de metade dos trabalhadores deste concelho tem uma profissão de alguma forma relacionada com a agricultura ou com a pesca ${ }^{10}$. $\mathrm{O}$ conhecimento prévio da realidade concelhia e a proximidade a alguns actores locais foi outro aspecto que entrou em linha de conta na selecção deste concelho, uma vez que a abordagem às formas como os habitantes constroem os territórios e como estes são representados pelos seus agentes já tinha sido iniciada numa outra pesquisa (Castro, 1999). Para além das características que do ponto de vista das dinâmicas territoriais Peniche apresentava, podem ainda salientar-se traços que fazem deste contexto um espaço com particularidades do ponto de vista da análise da integração em contexto migratório, a saber, a relevância de ser um concelho marcado pela emigração portuguesa para França e Canadá desde os anos 60, fenómeno que deixou marcas quer ao nível do acolhimento dado aos imigrantes, quer a outros níveis como por exemplo, ao nível da dinâmica do mercado habitacional de arrendamento.

A escolha do Alentejo para realizar outro estudo de caso residiu no facto de concentrar extensos territórios rurais, tendencialmente despovoados e envelhecidos onde os imigrantes poderiam ter vindo preencher necessidades de mão-de-obra em sectores de actividade deixados vagos. Ao mesmo tempo, colocou-se a hipótese de os meios rurais pro- porcionarem a estas famílias possibilidades de vida eventualmente geradoras de mudança nos projectos migratórios iniciais e indutoras de fixações de carácter mais permanente. Dada a extrema dispersão desta população imigrante, a sua forte mobilidade e ainda as dificuldades em aceder aos imigrantes, em virtude das situações de precariedade e muitas vezes de exploração em que trabalhavam e viviam, optou-se por não confinar a investigação a um único lugar, mas incidi-la em diferentes territórios em função dos locais de residência dos interlocutores que iam sendo indicados por informantes privilegiados. Entrevistaram-se, assim, imigrantes que de uma forma directa ou indirecta haviam tido contacto com o meio rural ou agrícola, embora residissem à altura nos meios urbanos de Beja e Montemor-o-Novo. Este trabalho de campo, contemplou a realização de observação participante durante 3 meses, tendo uma das investigadoras, durante este período, habitado com uma das famílias estudadas, mantendo com estes elementos um contacto estreito até ao final da investigação. Numa segunda fase, o trabalho de campo foi realizado numa associação de imigrantes sediada em Beja, a Solidariedade Imigrante de Beja. Aqui a investigadora trabalhou a tempo parcial executando as tarefas regulares de atendimento aos imigrantes. Desta forma foi facilitado o acesso aos imigrantes que viriam a constituir o painel de entrevistados deste estudo.

Outra das dimensões chave para a análise dos percursos migratórios correspondeu à incorporação de uma perspectiva temporal nos processos de integração a partir da noção de ciclo migratório e da selecção privilegiadamente de imigrantes em fases do ciclo que permitiam o equacionamento das questões que o reagrupamento familiar ou a constituição de família.

Por outro lado, a necessidade de considerar esta dimensão temporal do processo de integração conduziu à recolha de "histórias de família" como procedimento principal de produção da informação. Com esta abordagem metodológica pretendia-se não apenas obter um relato vivido dos percursos pes-

\footnotetext{
${ }^{9}$ Segundo dados do SEF relativos às Autorizações de Residência, Prorrogações de Autorizações de Permanência e de Vistos de Longa Duração em 2006, os imigrantes provenientes da Rússia, Moldávia, Roménia e Ucrânia eram 15 557, o que significa 20,4\% do total e o maior contingente distrital proveniente destes destinos.

${ }^{10}$ De acordo com os dados dos Censos de 2001, citados pelo Diagnóstico Social do concelho de Peniche, "No conjunto das profissões encontradas sobressaem como dominantes aquelas que dizem respeito à produção industrial e ao trabalho artesanal $(23,9 \%)$, ao pessoal do serviço de proteç̧ão e segurança, serviços pessoais e domésticos e trabalhadores similares $(15,8 \%)$, aos trabalhadores não qualificados da agricultura, indústria, comércio e serviços $(15,4 \%)$, e aos trabalhadores da agricultura e da pesca (11,2\%). Este documento conclui assim que os dados "deixam transparecer a influência da vocação piscatória e agrícola do município" (Rede Social, 2004: 101).
} 
soais de cada entrevistado, mas também aceder ao seu universo social e ao daqueles que lhe estão mais próximos. Através desta estratégia metodológica, cujos principais resultados não serão objecto de análise neste texto, procurou-se uma compreensão mais alargada do processo de integração, começando por compreender os mecanismos que conduziram aos problemas de desintegração nas sociedades de origem que sustentaram a decisão de migrar.

Expostas as opções teórico-metodológicas que estiveram subjacentes à investigação aqui parcialmente apresentada, serão abordadas as principais conclusões relativas às diferentes dimensões de análise dos processos de integração destes imigrantes. Estas dimensões são equacionadas em função das várias esferas de integração na sociedade portuguesa, considerando as variáveis (Pires; 2003), níveis de acolhimento (Portes, 1999) e traços (Machado, 1999) considerados relevantes para a análise dos processos de integração, procurando simultaneamente captar dinâmicas específicas em cada uma dessas áreas.

\section{Legalização}

A condição de estrangeiro encerra uma série de limitações no exercício de direitos e deveres no país de acolhimento, limitações essas que representam a marca do poder de soberania dos Estados que condicionam à aquisição de nacionalidade o estatuto de cidadão e portanto o acesso a esses mesmos direitos, nomeadamente direitos sociais, laborais e políticos. O grau de restritividade imposto pelos Estados no acesso aos direitos é definitivamente um elemento fundamental na compreensão dos processos de integração dos imigrantes podendo dar origem não só a fragilidades na sua posição laboral e social, mas contribuindo para o desenvolvimento de identidades reactivas em função de eventuais exclusões criadas. Importa assim perceber não só de que forma são restringidos os imigrantes pelo seu estatuto legal, mas também qual o papel das redes de relações sociais que propiciam ou dificultam o acesso a informação e conhecimentos imprescindíveis para ultrapassar os obstáculos e aproveitar as oportunidades contidas na lei.
Ao longo da última década, a legislação portuguesa aplicável à imigração tem sofrido avanços e recuos a orientações políticas diversas(Costa 2004, Pires 2003). As campanhas de regularização extraordinária da década de $90^{11}$ foram seguidas pela constituição de um quadro institucional destinado à integração desta população na sociedade portuguesa e pela promulgação de diplomas que alargavam os direitos dos imigrantes, revelando a extensão do objecto das políticas da imigração “(...) ao domínio da integração, em contraste com o centramento anterior no domínio da regulação dos fluxos." (Pires, 2003: 163).

Em Janeiro de 2001, o governo português publicou o Decreto Regulamentar 4/2001, alterando a configuração do quadro legal aplicável à imigração que fora instituído pelo Decreto-Lei 244/98. $\mathrm{O}$ artigo $55 .^{\circ}$ criou o regime das autorizações de permanência, destinado a vigorar até à aprovação do relatório das oportunidades de trabalho previsto no artigo $36 .^{\circ}$, tendo permitido a emissão de um visto com a duração de um ano (renovável até ao limite máximo de cinco anos) a todos os cidadãos estrangeiros em situação irregular que conseguissem provar possuírem um vínculo de trabalho subordinado ${ }^{12}$. De acordo com Pena Pires, "Contrariando a lógica de crescente informalização dos sectores de mercado de trabalho onde era mais forte a presença dos imigrantes em situação ilegal, a nova legislação remetia, pela primeira vez, para o reconhecimento de uma conexão entre funcionamento do mercado de trabalho e desenvolvimento de fluxos migratórios." (Pires, 2003: 166).

Através do regime das autorizações de permanência puderam legalizar-se 126901 cidadãos estrangeiros apenas em 2001. Segundo os dados do SEF, a emissão de autorizações de permanência continuou nos anos subsequentes, tendo até ao final de 2003 atingido o número total de 183655 A importância deste regime excepcional é visível também entre os entrevistados deste estudo: mais de metade obteve autorizações de permanência entre 2001 e 2003. A análise dos relatos sobre a regularização pelo regime das autorizações de per-

\footnotetext{
11 A campanha de regularização extraordinária de imigrantes de 1992 permitiu a legalização de 38 364 indivíduos, tendo a campanha de 1996 legalizado 29809 imigrantes (Cf. Costa, 2004: 64-66).

12 A emissão das Autorizações de Permanência ao abrigo do artigo 55. ${ }^{\circ}$ do Decreto Regulamentar 4/2001 de 10 Janeiro estaria sujeita ao preenchimento das seguintes condições por parte dos imigrantes em situação irregular: a) titularidade de proposta de contrato com informação da Inspecção-Geral do Trabalho; b) não terem sido condenados por sentença transitada em julgado com pena de privação de liberdade superior a 6 meses; c) não terem sido sujeitos a medida de afastamento do país; d) não estejam indicados para efeitos de não admissão no âmbito do SIS; e) não estejam indicados para efeitos de não admissão pelo SEF.
} 
manência permite-nos compreender a diversidade de situações à luz de dois factores que influenciaram de forma decisiva a fluidez (ou dificuldade) dos processos individuais de regularização: a relação com a entidade patronal e a dimensão relativa do contexto de fixação dos imigrantes.

Em primeiro lugar, a obtenção de autorizações de permanência dependeu da colaboração da entidade patronal, que deveria formalizar o vínculo de trabalho através da redacção de um contrato. A dependência da boa-fé dos patrões colocou alguns entrevistados numa situação de penosa vulnerabilidade. Outros, pelo contrário, enfatizaram as qualidades de carácter dos patrões, que cooperaram activamente no preenchimento das condições de admissibilidade ao regime das autorizações de permanência; outros salientam o receio com que os empregadores encaravam a hipótese de co-responsabilização pela ilegalidade laboral dos imigrantes.

Em segundo lugar, os relatos dos entrevistados revelam a influência do contexto de fixação dos imigrantes na fluidez do processo de regularização das autorizações de permanência. Aqueles que residiam em pequenas cidades beneficiaram da densidade das redes sociais locais. A menor dimensão dos contextos de fixação dos imigrantes pode criar as condições para uma relação de maior proximidade com os serviços locais do SEF e restantes entidades envolvidas na regularização de imigrantes. Bem diferente é a experiência dos imigrantes que viviam e trabalhavam em grandes centros urbanos.

Verifica-se, assim, que a relação dos imigrantes com o enquadramento legal que regula a sua entrada e permanência em Portugal mais do que uma relação estanque e unívoca, é o resultado de processos complexos de negociação e interacção social.

A experiência da ilegalidade pela qual quase todos os entrevistados passaram (sem contrato de trabalho, mal pagos, explorados na sua vulnerabilidade) deixou memórias dolorosas que o tempo vivido na legalidade não conseguiu apagar. Relativamente aos entrevistados chegaram entre 1997 e 2003, torna-se evidente que nenhum escapou a esta experiência, cuja duração variou entre alguns meses e cinco anos. Aqueles que chegaram até Novembro de $2001^{13}$, puderam beneficiar do regime das autorizações de permanência criado pelo artigo $55 .^{\circ}$ do Decreto-Lei n. ${ }^{\circ} 4 / 2001$. Os restantes, que entraram em Portugal depois desta data, só puderam regularizar a sua situação ao abrigo do artigo $71 .^{\circ}$ do Decreto Regulamentar n. ${ }^{\circ}$ 6/2004, que deu origem ao chamado "processo dos correios" .

Com a regularização, estes imigrantes viram abrir-se diante de si um novo mundo de possibilidades. Desde logo, desapareceu o medo e vulnerabilidade associados à situação irregular; com a emissão de títulos válidos, estes imigrantes libertaram-se da sujeição silenciosa a condições de trabalho deploráveis. Por outro lado, foi apenas após a legalização da sua estada em Portugal que os entrevistados se decidiram a visitar o país de origem; até esse momento, o medo de não poder regressar ao país de acolhimento obrigou-os a suportar como podiam a distância da vida dos que lá ficaram. Finalmente, a regularização da sua situação no território nacional permitiu que estes cidadãos estrangeiros pudessem aceder a prestações sociais ou a serviços bancários inacessíveis a imigrantes ilegais.

\section{Língua e educação}

O desconhecimento da língua portuguesa surge como a principal dificuldade sentida nos primeiros tempos em Portugal, constituindo a primeira barreira à integração quer a nível profissional, quer ao nível da consolidação dos laços sociais, quer ainda no acesso à informação sobre os próprios direitos.

A centralidade das aprendizagens informais, prevalecentes entre os imigrantes entrevistados, surge tanto pela escassez ou desconhecimento das ofertas de cursos de português para estrangeiros, como pela dificuldade de ter tempo para além do despendido no trabalho. Diferentes estratégias são desenvolvidas neste tipo de aprendizagem, muito apoiadas pela facilidade de manuseamento dos recursos linguísticos disponíveis: estudo individual ou com pares, apoio de portugueses e de outros

\footnotetext{
${ }^{3}$ De acordo com outros estudos publicados sobre imigrantes da Europa de Leste em Portugal, realizados a partir de amostras desta população, a maioria dos imigrantes desta região terá chegado entre 1997 e 2001, com maior número de entradas entre 2001 e 2001 (Cf. Fonseca et al. 2004 , Perista 2005).

14 Segundo informações do ACIDI do total de 53443 processos recebidos, 21,6\% do total (11 567) correspondiam a cidadãos moldavos (2371), romenos (3335), russos (921) e ucranianos (4940).
} 
imigrantes e importância do local de trabalho como espaço de sociabilidades. Embora reconhecendo as limitações destas formas de aprendizagem, no máximo passados dois anos os entrevistados consideram ter atingido algum nível de proficiência da língua portuguesa no entendimento e na locução. No entanto, procuram aperfeiçoá-la por via do acesso a cursos de português, situação nem sempre facilitada, sobretudo na área de Lisboa, pela escassez ou desconhecimento destes recursos nos seus contextos residenciais, mas também pela distância entre o local de residência e o local onde decorriam os cursos.

Se o contexto de trabalho é um local privilegiado para a aprendizagem inicial da língua portuguesa, mais tarde reconhecem-se as suas limitações, seja pelos fracos níveis de literacia dos colegas de trabalho, seja pelo tipo de trabalho que desenvolvem e que não exige a mobilização de grandes recursos linguísticos ou não permite a interacção (fábricas com níveis elevados de ruído, trabalho individual...). Outras situações dificultam também o processo de aprendizagem informal: a presença preponderante de imigrantes em determinados locais de trabalho, a situação de desemprego ou a escassez de contactos com portugueses.

À semelhança dos entrevistados, os seus filhos também sentem o desconhecimento da língua portuguesa como uma barreira no processo de integração. Neste caso concreto, os constrangimentos linguísticos manifestam-se ao ingressarem no sistema de ensino, reflectindo-se nas relações interpessoais com alunos e professores e no aproveitamento escolar em algumas disciplinas. Embora legalmente estejam previstas nas escolas actividades curriculares de apoio ao português como língua não materna, os jovens filhos dos imigrantes entrevistados contaram sobretudo com o apoio informal de alguns professores e com o envolvimento dos pais para encontrarem formas de ultrapassar a barreira linguística e contribuir para o sucesso escolar. Reconhecem-se limitações no domínio da língua portuguesa para fins académicos, o que tende a ser um factor de desmotivação ou de opção para regressar ao país de origem para terminar a escolaridade. O manejo de duas línguas em contexto familiar não impede contudo a mestria de ambas, parecendo ser a língua materna a que vai sendo mais sacrificada.

A associação entre o nível de aproveitamento escolar e a nacionalidade é referido por Dionísio: entre os estudantes melhor sucedidos nos estudos contam-se os nascidos na Moldávia, Suíça, Alemanha, Roménia e Ucrânia (Dionísio et al., 2005). Outros dados vão no sentido contrário, como os apresentados por Rosa (2005: 10) em que o abandono escolar revela uma "expressão importante" por parte de romenos e moldavos. No âmbito do estudo aqui apresentado, os dados recolhidos carecem de representatividade estatística para captar regularidades em termos do sucesso ou insucesso escolar, por nacionalidade ou por outras variáveis geralmente consideradas condicionadoras dos percursos escolares, como a condição de classe e os níveis de escolaridade dos pais.

Podemos, no entanto, enunciar duas situações que reflectem diferentes formas de integração dos jovens filhos de imigrantes em idade escolar. Por um lado, temos os casos de sucesso em que os jovens estão entre os melhores da turma. Por outro lado, encontra-se um conjunto de variáveis a condicionar o percurso escolar destes jovens que se reflecte ao nível da saída antecipada do sistema de ensino ou num fraco aproveitamento escolar. As situações relatadas prendem-se sobretudo com a influência do contexto residencial ou das redes sociais (fraca diferenciação social, bairros degradados, amigos em idade escolar que abandonaram o sistema de ensino...), do período da adolescência, mas também do fraco investimento e valorização do percurso escolar por parte de portugueses

As representações sobre o sistema de ensino português são construídas essencialmente através de uma avaliação comparativa com aquilo que se passava nos seus países de origem. É possível estabelecer dois perfis de entrevistados que se diferenciam pelo tipo de valorização que é dada ao ensino em Portugal. Aqueles que têm uma visão essencialmente negativa do sistema de ensino português, centram a sua avaliação nas fracas competências dos professores para exercerem as suas funções, mas também nos programas curriculares de algumas disciplinas como a matemática e a língua portuguesa e a programação do horário escolar. Critica-se a indisciplina na escola, a falta de respeito pelos professores, a ausência de estratégias de motivação dos alunos pelos professores e pela própria escola, o baixo nível de exigência que é pedido aos alunos e a grande carga horária que dificulta o estudo em casa. Os entrevistados que têm uma imagem positiva não se diferenciam 
dos anteriores em termos de perfil socioeconómico, nem de nacionalidade, mas tendem a ser pais de crianças a frequentar o $1^{\circ}$. ciclo do ensino básico. Comparando as experiências escolares dos seus filhos nos dois países acabam por valorizar positivamente a escola em Portugal. Uns destacam o menor nível de exigência como uma forma dos filhos se sentirem mais à vontade e motivados, mas também por não exigir dos pais um acompanhamento tão próximo. Outros dão nota positiva aos programas curriculares não fazendo qualquer distinção entre as disciplinas.

Alguns dos factores mais negativos associados ao percurso escolar ou às representações sobre o sistema de ensino tendem a ser superados pela criação de escolas para jovens filhos de imigrantes em que o ensino é ministrado na língua materna e os programas tendem a ser semelhantes ao dos países de origem ${ }^{15}$. Procura-se, assim, garantir a manutenção da aprendizagem como valor, que segundo alguns dos entrevistados o sistema de ensino português não promove. A par desta motivação que tem mobilizado grupos de imigrantes na criação destas escolas, aliam-se outros factores como a necessidade de superar dificuldades sentidas pelos alunos na escola portuguesa e valorizar a língua e cultura dos países de origem, mas também permitir, em caso de regresso, uma maior facilidade no processo de equivalências. A existência destas escolas permite também a alguns imigrantes exercer actividades de docência dificilmente alcançáveis numa escola portuguesa. Estas estratégias revelam alguma preocupação de natureza etnicizante ao se investir na perduração de elementos da "cultura de origem".

Apesar das inserções profissionais dos pais destes jovens não corresponderem às suas qualificações escolares, as suas expectativas face ao percurso escolar dos filhos passa por terminarem o ensino superior no sentido de terem uma profissão mais prestigiante e remunerada do que as suas.

\section{Percursos profissionais}

As inserções profissionais dos imigrantes no país de acolhimento são por excelência, o campo onde a questão da sua integração se joga de forma mais imediata. Desde logo, porque estamos a falar de migrações laborais, isto é, de pessoas que independentemente da complexidade dos motivos, saíram do seu país com o objectivo de encontrar trabalho mais bem remunerado. Por outro lado, porque a inserção laboral constitui uma das primeiras esferas de contacto com a sociedade de acolhimento e porque determina a posição estrutural na sociedade de destino e por essa via o acesso ou a exclusão de certos direitos, bem como o nível de recursos.

Independentemente de outros benefícios que a imigração possa ter trazido a estes imigrantes - uma vivência mais previsível, depois de todas as convulsões ocorridas nas suas sociedades de origem, a oportunidade de proporcionar à família condições de vida que eram vedadas nos países de origem, a libertação das pressões a nível profissional ou familiar (Matos et al., 2007) -, em termos de percursos profissionais, a tendência de mobilidade descendente que se vinha verificando antes da imigração não parece ter sido invertida, existindo bastantes casos em que ela persistiu. Grande parte das inserções dos imigrantes entrevistados correspondiam a actividades desqualificadas no sector secundário do mercado de trabalho (serventes, porteiros, operários da construção ou operários fabris e empregadas domésticas), perfis consentâneos com os dados conhecidos sobre as inserções dos imigrantes da Moldávia, Roménia, Rússia e Ucrânia ${ }^{16}$, ainda que se tenha entrevistado também pessoas nos subsectores menos desqualificados do Pessoal de serviços e vendedores; Pessoal administrativo e similares e Profissionais de nível intermédio. Não é só do ponto de vista do tipo de profissões desempenhadas que fica clara a inserção destes imigrantes no sector secundário. Também ao nível das condições do seu exercício é patente a desregulação a que estão sujeitas estas ocupações. tendo sido ao longo do trabalho de campo relatadas situações de exploração - horários muito para além das 40 horas semanais, remunerações abaixo do salário mínimo nacional, incumprimento das obrigações para com a Segurança Social por parte dos patrões, atraso nos salários ou horas extraordinárias

\footnotetext{
5 A título de exemplo refira-se a criação das escolas ucranianas em Portugal que conta com cerca de quinhentos alunos distribuídos por dez estabelecimentos pelo país. A escola de Lisboa funciona aos sábados e chegam a ter no ensino secundário onze disciplinas por dia, das 9h às 18:15h.

${ }^{16}$ Segundo os dados do Censos 2001, 35\% da população proveniente da Europa do Leste em Portugal tinha profissões desqualificadas, 43\% desempenhava profissões do grupo profissional dos operários, artífices e similares, $6 \%$ eram operadores de máquinas e instalações e trabalhadores da montagem, o que significa que $84 \%$ da população segundo os dados dos Censos estava nos grupos profissionais mais desqualificados.
} 
ou simples omissão de pagamento destas retribuições, subsídios ou indemnizações, bem como outro tipo de abusos de poder propiciados pela situação de fragilidade social e estatutária dos imigrantes. Nalguns casos, estes abusos eram generalizados, institucionalizados e tacitamente consentidas pelas autoridades, noutros claramente condenados em processo judicial.

Das especificidades trazidas por este contingente no panorama das migrações pode ainda apontar-se a presença em sectores até agora pouco procurados pelos imigrantes. É justamente no sector agrícola, mas também, no sector da indústria extractiva e transformadora que se verifica uma presença, até há poucos anos incipiente, de imigrantes de Leste. Esta presença que os dados disponíveis têm documentado ${ }^{17}$, está espelhada no tipo de sectores de actividade que surgiam nos percursos dos entrevistados. A análise contextual permitiu perceber não só a incidência da agricultura, em Peniche e no Alentejo, e da indústria, sobretudo em Peniche, nestes percursos. Foi ainda possível retirar conclusões importantes sobre as diferenças do regime de prática agrícola em cada um dos contextos, de esquemas de trabalho muito mais intensivos no Alentejo, aos quais pudemos aceder muito superficialmente, que dão de alguma forma conta da realidade da moderna agricultura praticada sobre o antigo regime de propriedade latifundiária e exploração intensiva dos trabalhadores, característicos desta região, agora com as novas roupagens do dumping social dos países europeus por relação aos imigrantes e sobretudo, àqueles que estão em situações irregulares. Em Peniche, a prática agrícola surge sobretudo como parte de esquemas de pluriactividade e plurirendimento, aliás bem característicos do modelo económico português (Santos; 1987; Almeida; 1982). A pluriactividade não se restringe contudo, ao trabalho agrícola tendo sido encontrados exemplos de jornadas de 12, 14 e até 18 horas de trabalho em vários contextos.

Apesar da fragilidade da sua posição, não é sempre passivamente que vivenciam estas situações. É assim crítica a leitura do olhar estrangeiro sobre a cultura organizacional portuguesa, surgem apreciações negativas, de falta de capacidade reinvindicativa, de capacidade de inovação e de autonomia por parte dos trabalhadores portugueses e de falta de qualidades de liderança, baixos níveis de qualificações e fraca consciência cívica por parte dos patrões. Mais do que apenas apreciações, surgem também reacções explícitas aos tratamentos injustos de que são alvo, que vão desde a interpelação dos patrões no sentido de alterarem o seu comportamento até à judicialização destas injustiças.

Perante o confronto com estas situações, o discurso sobre as situações presentes contrastantes com os lugares assumidos nos países de origem antes das transformações introduzidas pela Perestroika, alterna entre uma resignação auto-imposta e o desencanto e a frustração assumida. Os projectos profissionais em Portugal ou projectos de mobilidade ascendente no país de origem surgem em muitos casos, assim, como um ponto de fuga destes sentimentos, projectando-se nelas a justificação para as renúncias presentes.

Ainda que praticamente todos tenham passado pelo mercado secundário de emprego nas suas primeiras experiências laborais, o investimento em novas qualificações ou o reconhecimento daquelas que tinham sido adquiridas nos países de origem, a instalação por conta própria, a inserção em nichos étnicos do mercado de trabalho português ou o trabalho para organizações portuguesas dirigidas a imigrantes, foram para algumas destas pessoas, estratégias de mobilidade que lhes permitiram fugir às inserções mais desqualificadas. Este é também o tipo de estratégias enunciadas nos projectos profissionais equacionados pelos imigrantes. Do ponto de vista das formas de integração dos imigrantes entrevistados na sociedade portuguesa, equacionada nos termos da assimilação ou da etnicização, a análise dos percursos profissionais revela indícios de mobilidade mas no sentido da incorporação em modalidades menos étnicas, eventualmente no mercado primário de emprego (Portes, 1999). A desetnicização dos mecanismos de acesso ao mercado de trabalho, nem sempre linear e a pouca expressão que parece ter nos projectos a criação de economias étnicas viradas para os consumos específicos dos imigrantes de Leste ou para as disponibilidades

Segundo dados dos Quadros do Pessoal 2000-2002 citados por Carneiro (2006), em 2002, 77,3\% dos trabalhadores imigrados na agricultura, produção animal, caça e pesca; $65,2 \%$ nas indústrias transformadoras e 86,4\% nas indústrias extractivas era originário dos países da Europa de Leste. 
de consumo étnico da sociedade de acolhimento, parecem comprovar esta tendência.

\section{Habitação e mobilidade territorial}

Os itinerários residenciais são o resultado de dinâmicas sociais complexas e revelam a forma como os indivíduos se projectam no espaço-tempo da migração e do enraizamento num dado território. A questão residencial é assim indiciadora da orientação ao nível dos projectos migratórios e das modalidades de integração nas sociedades de acolhimento, traduzidas quer através dos mecanismos de acesso à habitação, quer do grau de concentração étnica. De acordo com os relatos recolhidos, o local para a primeira fixação assenta numa esfera de interconhecimento ou é o resultado das redes organizadas de imigração. Nuns casos, os sujeitos instalam-se onde já têm família ou membros conhecidos da mesma vaga migratória, noutros casos, mais raros, o lugar de chegada depende da localização e do conhecimento de certos intermediários que poderão garantir a possibilidade de encontrar um alojamento e trabalho. Neste sentido, é possível verificar alguns efeitos das estratégias utilizadas para migrar, mais ou menos suportadas em mecanismos informais.

É a existência no local de chegada destas redes sociais, familiares ou formais que num primeiro momento garante o acesso relativamente facilitado a um alojamento, permite contornar o desconhecimento da língua e a insuficiência de rendimentos. Mas a primeira residência é por todos avaliada como sendo precária e com más condições de habitabilidade, seja pela necessidade de a partilharem com outras pessoas, seja pelo deficiente estado de conservação e condições que oferece. Esta situação é encarada como uma estratégia económica que visava despender o mínimo de recursos, muito ancorada num projecto migratório temporário sobretudo iniciado por indivíduos que chegaram sozinhos com o objectivo de encontrarem um trabalho que permitisse manter a subsistência da família no país e pagar as dívidas entretanto contraídas.

O tempo de permanência em situações habitacionais indesejadas é muito variável de caso para caso, podendo ir de um mês a cinco anos. É difícil estabelecer uma regularidade em termos de perfil social daqueles que conseguem mais facilmente encontrar uma situação residencial mais consentânea com as suas expectativas, mas em termos globais é possível concluir que a maior estabilidade profissional e/ou o apoio de portugueses na procura de alojamento são duas variáveis que interferem positivamente na inflexão dos percursos residenciais.

Ao longo das trajectórias residenciais analisadas um conjunto de factores intervêm na sua estruturação. Encontramos, assim, acontecimentos familiares (nascimentos, divórcios, chegada da mulher e dos filhos...) a influenciarem a mudança de residência, mas também constrangimentos económicos, tais como o estatuto do emprego e o nível de rendimentos, a localização do trabalho, a perda de emprego, o aumento da renda, ou oportunidades favoráveis como a promoção profissional, o acesso a um empréstimo e a entrada da mulher no mercado de trabalho. Os efeitos das redes não deixam também de ser menos importantes e traduzem-se em oportunidades que favorecem o arrendamento, o empréstimo e/ou a ocupação de um alojamento, podendo elas ser de diferentes tipos (familiares, comunitárias, associativas, religiosas, profissionais, de vizinhança, formais). Encontra-se ainda a estruturar estas trajectórias os factores residenciais assentes na avaliação das vantagens ou inconvenientes do alojamento e do bairro, nomeadamente o desejo de não viver numa casa partilhada, o gosto pela centralidade urbana ou pela proximidade de transportes públicos.

Analisando estes contextos residenciais constata-se uma tendência para a dispersão mesmo quando as redes étnicas tiveram algum papel no acesso à habitação. No entanto, em localidades mais pequenas, como é o caso de Ferrel, no concelho de Peniche, é possível verificar alguma concentração, mais como resultado das dinâmicas do mercado de arrendamento do que como estratégia residencial.

$\mathrm{O}$ acesso à propriedade em Portugal faz parte de uma trajectória residencial que reflecte as expectativas de permanência no país de acolhimento e traduz um investimento económico, mas também simbólico. Diferenciações entre contextos em termos do mercado imobiliário e da intensidade dos laços sociais que se foram gerando interfere no tempo necessário para concretizar esta aspiração, destacando-se o concelho de Peniche onde o acesso se deu mais cedo e onde parece ser mais evidente o enraizamento territorial. Entre aqueles que ainda não concretizaram o desejo de compra, o projecto de retorno é incerto ou perspectiva-se quando os 
filhos terminarem a escolaridade. Mas mais do que a indefinição do projecto migratório, são outros os constrangimentos que condicionam o acesso à propriedade. Os entrevistados mais novos, que ainda não constituíram família ou aguardam a chegada dos seus familiares incluem-se entre aqueles que manifestam inserções territoriais mais instáveis fruto de situações laborais mais precárias, ou da instabilidade relacional com co-arrendatários. No entanto, não deixam de manifestar desejo de procurar a melhoria da sua situação residencial.

$\mathrm{O}$ investimento na progressiva melhoria das condições habitacionais em Portugal não tende a quebrar as ligações com o país de origem, colocando os entrevistados "nos dois caminhos" e intensificando-se as interdependências entre os dois países seja a nível residencial, através de investimentos de duplo sentido, seja noutros domínios que adiante se analisarão como a saúde. Estes investimentos de duplo sentido não deixam de indicar que a fixação em Portugal dos imigrantes entrevistados está em curso, o que implica equacionar a sua integração não como provisória, mas de maior duração, nomeadamente ao nível da relação com as instituições locais (educação, saúde, segurança social...) e com a política.

\section{Acolhimento pela sociedade portuguesa e relações interétnicas}

Se não se pode dizer que é plenamente aceite a presença destes imigrantes em Portugal, também não seria correcto referir a existência de um fenómeno de estigmatização generalizada, um dos factores que é apontado como potenciador de integrações mais etnicizadas ou de contraste. Contudo, as informações recolhidas por esta investigação, indiciam alguns pontos de fricção entre a sociedade portuguesa e os novos residentes do leste europeu, designadamente em alguns sectores do mercado de trabalho, no quadro de instituições em que a cobertura é deficiente como a saúde ou mesmo a um nível contextual mais generalizado. Estes atritos podem ser relacionados com um sentimento de ameaça por parte dos portugueses relativamente à presença dos imigrantes.
No que diz respeito ao meio laboral, é sobretudo em contextos mais alargados, como as unidades industriais e na construção civil, que essas expressões de hostilidade se fazem sentir. A imagem de boa interacção entre os imigrantes de Leste e os portugueses sofre aqui um dos seus maiores contraditórios. Se surgem referências ao bom desempenho e profissionalismo destes trabalhadores $^{18}$, as situações de discriminação por parte de patrões, mas sobretudo, as situações de fechamento defensivo por parte de colegas surgem várias vezes relatadas nas entrevistas. Este tipo de situações aparecem sobretudo, em contextos de trabalho mais alargados, como é o caso da indústria, em que a força das dinâmicas de grupo no sentido do nivelamento dos comportamentos e da anulação de desempenhos destacados da norma, faz sentir a estes imigrantes como a sua capacidade produtiva acrescida não é bem-vinda entre os pares.

Em termos territoriais, o fechamento social, a inexistência de história migratória e um menor dinamismo económico parecem estar relacionados também com acolhimentos mais hostis. Este conjunto de condicionantes explica talvez que o Alentejo seja o território com mais testemunhos de hostilidade face aos ucranianos, moldavos, russos e romenos entrevistados. Por seu lado, a própria dinâmica intraétnica parece aqui relativamente débil, quer nas suas expressões mais informais, quer nas suas expressões mais institucionalizadas como as associações. Pode verificar-se mesmo efeitos de evitamento que podem estar justamente relacionados com a fragilidade da posição destes imigrantes, e com o facto de as redes não constituírem em si um recurso para a integração.

Se estas dinâmicas estão presentes sobretudo no contexto alentejano pode dizer-se que elas foram encontradas também noutros contextos. Apesar de se ter evidenciado a importância do papel das redes étnicas no acesso a componentes mais instrumentais da existência, como o acesso ao trabalho, à habitação, etc., elas não parecem configurar de modo muito forte as sociabilidades ou os sentimentos de pertença dos imigrantes. Pode equacionar-se também a possibilidade de serem as sociabilidades étnicas anuladoras dos efeitos de anonimato que

\footnotetext{
${ }_{8}^{8}$ Outros estudos (Carvalho, 2004) referem-se especificamente à produtividade acrescida que tinha sido introduzida nas empresas que contratavam imigrantes de Leste. Este acréscimo de produtividade é atribuído à maior assiduidade, competência técnica, dedicação ao trabalho e esforço produtivo.
} 
resguardariam os imigrantes de se confrontarem com situações de insatisfação que as suas inserções poderiam provocar, sobretudo em contextos em que as oportunidades económicas são menores e essa insatisfação é maior.

O ciclo migratório é aqui importante para explicar estas dinâmicas, na medida em que o trabalho é ainda um forte pólo de estruturação dos quotidianos e dos projectos migratórios de muitas destas pessoas, mesmo quando o reagrupamento familiar se tenha já dado.

Nos testemunhos de maior proximidade com os co-étnicos, a existência de pólos institucionais agregadores, como igrejas ou escolas de língua, escolas para ensino da língua do país de origem aos mais jovens, pareceu também ter alguma influência na geração de dinâmicas de mobilização intraétnica.

No que diz respeito ao fenómeno associativo encontrou-se um generalizado desinteresse ou mesmo desconfiança relativamente ao envolvimento ou ao recurso a associações de imigrantes que pode ser relacionado mais uma vez com a centralidade da vida profissional e com disposições subjectivas menos favoráveis à acção colectiva. A transitoriedade dos projectos migratórios, bem como algumas actuações menos clara por parte de associações de imigrantes equacionadas por alguns autores (Pires, 2004) podem constituir-se como uma explicação para este desinteresse.

\section{Segurança Social}

O contributo dos imigrantes para o Sistema de Segurança Social tem vindo a ser salientado pelo saldo positivo relativamente às contas do Estado, destacando-se particularmente o grupo dos cidadãos provenientes dos países da Europa do Leste ${ }^{19}$. A vinculação do estatuto legal à existência de uma carreira contributiva como aconteceu no processo dos correios e a responsabilização das entidades patronais que foi reforçada com o Decreto-Lei 4/2001contribuiu para esta entrada massiva de contribuintes.

Contudo, ao aumento de receitas que tem gerado, não corresponde um valor de benefícios pagos ou um tratamento justo por parte dos serviços. Tem contudo, existido um esforço por parte do Estado português de corrigir o quadro legal português para que essas situações sejam atenuadas. Desse esforço é exemplo, o Decreto-lei n. ${ }^{\circ}$ 41/2006 no sentido do reconhecimento do direito às prestações familiares aos filhos dos imigrantes em Portugal que não têm Autorização de Residência.

Contudo, as fragilidades da protecção social aos imigrantes são apontadas por vários entrevistados, nomeadamente, o facto de nem todas as pessoas singulares activas poderem alimentar o mesmo tipo de expectativas quanto à sua reforma. De facto, a garantia de protecção social na velhice a cidadãos estrangeiros é feita através de normas internacionais que são celebradas de forma multilateral ${ }^{20}$ ou bilateral $^{21}$ e que incluem apenas, entre os entrevistados para esta investigação, os romenos.

Contudo, nem todas as falhas estão na arquitectura das leis e normativos. Se são frequentes os testemunhos que diferenciam o tratamento dado nas instituições de saúde daquele que receberam nos serviços de Segurança Social, valorizando este último, alguns imigrantes referem tratamentos discriminatórios e até de abuso de poder e usurpação de direitos alheios, praticados com base numa representação dos imigrantes como ignorantes, desinformados e genericamente passivos face ao mau funcionamento dos sistemas.

Finalmente, outras situações de injustiça surgem por parte das entidades patronais, penalizando quer as possibilidades de legalização dos imigrantes, quer as suas carreiras contributivas e ainda o próprio sistema. Existem assim vários relatos de inexistência de cumprimento das obrigações contributivas por parte dos patrões, resolvidas de formas

\footnotetext{
19 Pela sua elevada taxa de actividade, os estrangeiros têm sido uma fonte de contribuições para o Sistema de Segurança Social português. Com uma das mais elevadas taxas de actividade entre os grupos estrangeiros a residir em Portugal, constituíam em 2004, segundo dados do IIESS - Ministério da Segurança Social e do Trabalho (cit. por ACIME; 2005) quase 30\% dos contribuintes estrangeiros (139 035 pessoas) ultrapassando quer os imigrantes oriundos dos PALOP no seu conjunto (27,6\% correspondentes a 134625 contribuintes) e os brasileiros (19\% isto é, 92821 indivíduos), o que confere a este grupo o primeiro lugar entre as pessoas singulares estrangeiras activas na Segurança Social, com um crescimento relativamente ao ano de 2000 de mais de $800 \%$.

${ }^{20}$ No âmbito multilateral, existem Regulamentos Comunitários sobre Segurança Social abrangendo os 27 Estados da União Europeia, bem como a Islândia, o Lichenstein e a Noruega, que são parte do Espaço Económico Europeu, e ainda a Suíça, no quadro do Acordo sobre livre circulação de pessoas celebrado entre a Comunidade Europeia e os seus Estados membros e a Confederação Helvética.

${ }^{21}$ No âmbito das convenções ou acordos celebrados bilateralmente os países abrangidos são Andorra, Argentina, Austrália, Brasil, Cabo Verde, Canadá, Canadá-Quebeque, Chile, Estados Unidos da América, Marrocos, Reino Unido em relação às Ilhas do Canal (Jersey, Guernesey, Alderney, Herm, Jethou e Man), Uruguai e Venezuela.
} 
diferentes. Este contudo, não é comportamento que afecte exclusivamente os imigrantes.

Apesar destas fragilidades, as opiniões dos imigrantes quanto ao funcionamento do sistema de Segurança Social dividem-se. A par do registo de uma maior eficácia dos serviços nos respectivos países e do valor mais baixo das contribuições, salienta-se o valor mais elevado dos benefícios recebidos em Portugal.

\section{Saúde}

O acesso ao Sistema Nacional de Saúde (SNS) por parte dos imigrantes entrevistados depara-se com uma série de obstáculos ao nível da logística associada ao atendimento, do processo terapêutico e dos cuidados prestados. Apesar de alguns destes obstáculos traduzirem problemas de funcionamento do sistema de saúde público que não afectam exclusivamente os imigrantes, outros reflectem a falta de preparação do pessoal médico para lidar com a diferença, registando-se situações de discriminação associadas à escassez de recursos e à ameaça dos imigrantes como potenciais usurpadores de benefícios, mas também à falta de formação profissional e de sensibilização para que as políticas em matéria de saúde possam ser concretizadas ${ }^{22}$. Situações relatadas relativamente às barreiras linguísticas entre paciente e profissional de saúde na tradução de alguns problemas de saúde leva os imigrantes a recorrer a diferentes unidades de saúde numa tentativa de compreensão do problema, com repercussões no funcionamento dos serviços, mas também no desgaste das famílias.

Parte dos constrangimentos encontrados tendem a ser colmatados nos territórios em análise por organizações da sociedade civil seja pela disponibilização de informação sobre os direitos à saúde, seja pela concretização de acções específicas no âmbito de projectos locais, seja pelo estabelecimento de protocolos com médicos privados. Estes recursos resolvendo pontualmente algumas situações, não se revelam no entanto suficientes e levam os imigrantes a contornar os obstáculos encontrados de diferentes formas, nomeadamente através do recurso à auto-medicamentação, a médicos associados às empresas onde trabalham, ao sistema privado de saúde, às urgências hospitalares perante situações que não exigem uma intervenção imediata.

O descrédito e o desconhecimento de médicos portugueses, mas também a morosidade inerente ao SNS conduzem os imigrantes, mas também os seus amigos portugueses a recorrer também a cuidados de saúde no país de origem. De facto, alguns relatos de tratamentos na Roménia, na Moldávia e na Ucrânia revelam rapidez e economia, tornando-se mais vantajoso pagar a viagem do que ter de esperar por uma intervenção em Portugal. Mas para além destas vantagens tem-se a garantia do tratamento ser feito por um médico competente.

Grande parte dos constrangimentos enunciados no acesso ao SNS são sobretudo colocados numa fase do percurso migratório em que a presença da família exige um maior contacto com este tipo de instituições, tornando mais evidentes os efeitos da permanência nas formas de integração, e no caso concreto da saúde exigindo respostas mais satisfatórias.

\section{Que integrações?}

A discussão das questões da integração tem sido remetida para um tempo de permanência que, segundo os autores, pode corresponder ao momento de reagrupamento familiar (Machado, 1999) ou mesmo, ser colocada apenas na segunda geração (Portes, 1999).

Sendo o surgimento do fluxo de imigração proveniente dos países de leste europeu, relativamente recente, parece contudo, não só viável, como muito pertinente discutir a questão da integração na sociedade portuguesa de um conjunto alargado de pessoas que tem experiências de permanência já relativamente longas, que estabeleceu aqui os seus laços com um conjunto de instituições, que contribuiu com o seu trabalho para a produção de bens ou serviços em Portugal, que trouxe as suas famílias e que nalguns casos tem projectos de permanência no nosso país. A incidência prevalecente das entrevistas em casos de famílias de imigrantes suporta esta convicção de que a integração destas pessoas na sociedade portuguesa pode e deve ser objecto de reflexão. Mais do que meros agentes económicos, é de agentes sociais que se trata, pes-

\footnotetext{
${ }^{22}$ É reconhecendo estas dificuldades que em parte se elegeu como tema da saúde para a presidência portuguesa da União Europeia em 2007: "Saúde e Migrações".
} 
soas que construíram aqui a sua vivência e para quem a permanência em Portugal passou a ser um parêntesis cada vez mais envolvente.

Se é de integração que se fala, importa então, discutir as suas modalidades e aquilo que os cenários actuais podem indicar sobre tendências futuras. Se se utilizar como referência os modelos complementares de Rui Pena Pires (2003) e Fernando Luís Machado (1992, 1999), relativos aos traços e factores que determinam o posicionamento dos modos de integração num contínuo que tem como pólos a noção de continuidade (Machado, 1999) ou assimilação (Pires, 2003) e de contraste (Machado, 1999) ou etnicização (Pires, 2003), podemos orientar esta análise de síntese de modo a salientar as principais conclusões.

À partida, e considerando as dimensões sociais de análise de contrastes e continuidades, os traços parecem dar um retrato de contraste com a sociedade portuguesa. Fazendo uso dos dados quantitativos disponíveis sobre a população das nacionalidades seleccionadas neste estudo, torna-se evidente que com uma relação de masculinidade favorável aos homens e uma estrutura demográfica relativamente jovem ${ }^{23}$, a estrutura demográfica da população imigrante destas nacionalidades apresenta um contraste claro com a estrutura da população portuguesa, sobretudo no topo. Por outro lado, entre os imigrantes entrevistados, verifica-se uma forte tendência de proletarização ${ }^{24}$ e uma precarização do mercado de trabalho em que se inserem, situando-os, de novo, do lado dos contrastes sociais relativamente à população portuguesa. Contudo, este cenário complexifica-se quando se tomam em consideração outras variáveis indicativas do lugar ocupado no eixo dos contrastes e continuidades sociais, como seja a escolaridade e a situação residencial.

É de facto paradoxal a condição destes imigrantes que vêem contrastada a sua posição na hierarquia das profissões com as suas qualificações ${ }^{25}$. De facto, a este nível trata-se de um contraste "para cima". Também quando se considera o factor mobilidade social é possível verificar que existem projectos e, em alguns casos, esforços bem sucedidos no sentido da fuga à desqualificação profissional que caracteriza as inserções profissionais de parte importante destas pessoas. Eles podem passar pelo investimento no capital humano ou na inserção por conta própria. No que diz respeito à geração mais nova, os dados recolhidos quer por inquéritos mais sistemáticos, quer através das entrevistas realizadas neste estudo apontam em sentidos contrários, reflectindo por vezes, a influência dos contextos na desvalorização da escola.

Outro indicador de continuidade no eixo relativo às dimensões sociais do posicionamento destes imigrantes no espaço da etnicidade, diz respeito à localização residencial. De acordo com aquilo que foi possível observar relativamente a estes imigrantes, é de dispersão a tendência de fixação não só no território português, como também ao nível dos percursos residenciais. Se exceptuarmos o caso de Ferrel em Peniche, não se verificou qualquer efeito de aglomeração residencial, mesmo quando as redes étnicas tinham tido algum papel no acesso à habitação.

Relativamente às dimensões culturais, se a religião não foi uma dimensão desenvolvida na análise aqui apresentada, pode contudo dizer-se que não existem à partida grandes marcas de contraste, nem elas são muito estruturantes do modo de vida destes imigrantes. No que diz respeito à língua, ela é sem dúvida, um importante factor de contraste, constituindo a par do estatuto legal, um dos maiores obstáculos às inserções laborais e sociais dos imigrantes de Leste em Portugal e mesmo dos seus filhos. Parece haver, contudo, apesar da centralidade que o trabalho assume na organização do quotidiano, uma predisposição para a aprendizagem da língua que se reflecte na forma angustiada como são vividas as limitações de comunicação e nos esforços que são empregues para as ultrapassar. Por outro lado, e fazendo a associação com outra das dimensões do eixo dos contrastes e continuidades culturais, a pouca densidade das redes intraétnicas

\footnotetext{
$\overline{23}$ Segundo dados do SEF, a população de russos, moldavos, romenos e ucranianos com menos de 15 anos era $16 \%$, valores muito próximos dos registados na população portuguesa $15,6 \%$ em 2005. Contudo a população com mais de 65 não chegava a $1 \%$ dos indivíduos com autorização de residência em 2005, contra os $17,1 \%$ entre a população residente em Portugal.

${ }^{24}$ Cf. nota 16.

25 Segundo dados do Censos do INE, 36,3\% dos russos, $28 \%$ dos moldavos, $16 \%$ dos romenos e $27,3 \%$ dos ucranianos tinham completado o ensino superior o que contrasta com os $5 \%$ da população portuguesa na mesma data. Por seu lado, a taxa de analfabetismo era de $3,7 \%$ para russos, $2,3 \%$ para moldavos, $3,6 \%$ para romenos e $3 \%$ para os ucranianos, quando em 2001 ela era de $15 \%$ para os portugueses.
} 
parece constituir igualmente um importante factor de socialização na língua. Deste ponto de vista, este parece um traço de contraste a evoluir no sentido da aproximação, por via da aquisição das competências de comunicação em língua portuguesa, que eram inexistentes à partida.

Mas a importância das sociabilidades na configuração da posição que os imigrantes ocupam no espaço da etnicidade vai para além das repercussões que tem na língua. Ela é fundamental para a determinação da forma como o factor étnico é definidor da participação na sociedade de chegada, isto é, nos termos de Machado (1992; 1999) do seu grau de etnicidade.

Importa notar que a definição do tipo de sociabilidades está, para grande parte dos imigrantes, muito condicionada pelos constrangimentos impostos por uma forte absorção do seu tempo pelas actividades laborais, sendo sobretudo nos contextos em que os salários são mais baixos que esta tendência se torna mais evidente. Quando esse factor se atenua, como é o caso do contexto lisboeta, curiosamente surgem duas tendências muito marcadas com manifestações de preferência pelas sociabilidades portuguesas e mesmo de indícios de evitamento relativamente aos compatriotas, mas também de interacções intraétnicas relativamente fortes. De qualquer forma, mesmo nos casos em que as sociabilidades intraétnicas são mais fortes, não existe propriamente fechamento às interacções com a sociedade maioritária. Outro aspecto particular é o papel das instituições na criação destas sociabilidades, sendo que, dada a insipiência de grande parte das instituições étnicas, é muitas vezes no âmbito das relações geradas no âmbito de iniciativas das instituições portuguesas para imigrantes que surgem estas interacções. De qualquer modo, os testemunhos de mal-estar relativamente aos compatriotas e à sua atitude pouco solidária em contexto de imigração são marcantes nas entrevistas realizadas, dando conta de uma realidade em que o factor étnico não é muito saliente.

Se se tiver em atenção o modelo de Pires (2003: 102-110), orientado para a identificação dos factores produtores de etnicização, pode-se procurar alguns factores explicativos para este comportamento na fraca ancoragem do fluxo em redes étnicas informais que se relaciona com a sua natureza recente, com a ausência de laços históricos significativos e eventualmente com a posse de alguns recursos qualificacionais que têm sido apontados como potenciadores de orientações mais cosmopolitas (Jansen 1969 cit. por Pires; 2003: 93).

Por seu lado, relativamente às reacções sociais à imigração, dimensão enunciada por Portes (1999: 29-32) e Pires (2003: 107-109), podemos constatar que em relação aos imigrantes de Leste, e apesar de algumas ambiguidades quer da imprensa, quer da opinião pública, registadas nalguns estudos realizados nos últimos anos em Portugal (Lages, 2006; Sabino, 2006; Cunha, 2006), não se pode afirmar que tenha sido ou seja de sentido negativo o acolhimento por parte da sociedade portuguesa, existindo alguns indícios de uma diferenciação positiva destes imigrantes.

Uma análise contextual como aquela que esta investigação propicia dá relevância a outros factores na configuração das formas de acolhimento, tais como o dinamismo da economia e dos mercados de emprego - especialmente penalizador no caso do Alentejo, onde se repetem relatos de discriminação, sobretudo em ambiente laboral. Por outro lado, parecem emergir características associadas à natureza das relações sociais nos contextos estudados que definem maiores níveis de aceitação do novo e do estranho em contextos mais urbanizados e de maior dimensão do que em contextos mais pequenos e com características mais "comunitárias", com todas as cautelas que se possam colocar à atribuição desta categoria às características da interacção social em contextos como Peniche e Beja, por exemplo. Desta forma, Lisboa surge com menos relatos de hostilidade, ainda que também com menos descrições de manifestações de solidariedade, sendo estas recebidas sobretudo em contexto institucional, contrariamente ao que sucede em Peniche, em que vêm sobretudo dos relacionamentos de proximidade as experiências de bom acolhimento. Finalmente, questões relacionadas com a história migratória dos contextos também parecem muito importantes para a determinação de acolhimentos mais ou menos favoráveis. Este aspecto emerge em Peniche com bastante saliência, sendo visível uma projecção das dificuldades sentidas por portugueses com experiência migratória nestes imigrantes, e que encontra tradução em diversas formas de solidariedade e apoio, sobretudo na fase inicial da sua integração.

Outro aspecto que parece emergir desta análise é a especificidade das formas de acolhimento 
no meio laboral. É aqui que a hostilidade dos portugueses parece ter maior expressão, já que o perfil qualificacional, bem como a cultura organizacional e de trabalho dos imigrantes de Leste parece ser vista como uma ameaça às normas de desempenho, estabelecidas de modo formal ou informal. É, sobretudo, em contextos mais alargados como as unidades industriais, as empresas de limpezas, os estaleiros de obras de construção civil que esses comportamentos são identificados. Pelo contrário, contextos de trabalho mais restritos não surgem tão frequentemente associados à experiência de hostilidade por parte dos portugueses. Este factor pode também contribuir para explicar as diferenças de género encontradas na incidência de sentimentos de estigmatização, já que à excepção de Peniche, em que as unidades industriais empregam bastantes mulheres, as inserções das mulheres são normalmente em organizações mais pequenas ligadas por exemplo, à restauração, ou mesmo no contexto familiar do trabalho doméstico.

Outros factores de atenuação dos efeitos daquilo que Tom Burns e outros (2001 cit. por Pires, 2003: 107) designa por outrismo podem ser associados às características deste fluxo: a proveniência de sociedades com um nível de organização e desenvolvimento semelhante ou superior aos da sociedade portuguesa e o próprio percurso qualificacional e profissional dos moldavos, romenos, russos e ucranianos presentes em Portugal, mais uma vez superior ao da generalidade dos portugueses.

No campo das políticas nacionais, outro dos níveis de recepção dos imigrantes, é importante considerar dois aspectos. Por um lado, a geração de hiatos entre o desenvolvimento real do fluxo e a restrição das políticas de entrada, situação que determinou a geração de fenómenos de ancoragem das entradas em redes, neste caso em redes organizadas que, apoiando a deslocação e todos os trâmites de entrada, criavam também situações de exploração e de logro que podiam ocorrer na viagem, mas que normalmente surgiam à chegada a Portugal. Por outro lado, o acesso dos imigrantes aos direitos, normalmente vinculado a questões de estatuto legal e de relação com o mercado de trabalho.

Neste caso, pode registar-se a importância das redes e das características dos contextos estudados no acesso à informação por parte dos imigrantes, bem como na capacidade de controlo das autoridades sobre situações de irregularidade, tendo tido as relações informais e os efeitos acrescidos de controlo social em meios pequenos um efeito benéfico sobre a possibilidade de aceder a um estatuto legal na sociedade portuguesa.

Do ponto de vista dos direitos, tem existido nos últimos anos um esforço de garantia e cumprimento de compromissos de nível nacional e internacional com a promoção do acesso a direitos sociais por parte dos imigrantes. São, contudo, reactivas as iniciativas do Estado português, criando situações de injustiça e de exclusão dos imigrantes face aos direitos de protecção social e saúde, geradas pela actuação extemporânea e pela arbitrariedade dos serviços na atribuição de benefícios face às incongruências entre o quadro normativo mais genérico dos direitos individuais e a sua tradução legal. Estes efeitos têm de ser relativizados, no caso da saúde, por exemplo, já que as situações descritas nas entrevistas não parecem resultar propriamente de um acesso dificultado aos imigrantes, mas de um mau funcionamento generalizado do sistema.

Concluindo, com um balanço enunciado nos termos dos quadros de referência que usamos para analisar as integrações -, ainda que as fortes limitações ao nível das políticas restritivas às entradas e os factores de contraste cultural relativamente à população portuguesa, como é a língua, imponham inserções de contraste social características das imigrações laborais em Portugal -, não parece que o caso dos imigrantes entrevistados neste estudo e os imigrantes de Leste, em geral, configure uma situação de "duplo contraste" (Machado, 1999: 120) como é o caso de grupos posicionados em situações semelhantes do ponto de vista das inserções laborais, como é o caso dos cabo-verdeanos. As elevadas qualificações, as vivências em sociedades que conheceram níveis de organização e complexidade significativos e nas quais as instituições eram relativamente eficazes a garantir os direitos e as necessidades instrumentais básicas, parecem predispor estes imigrantes a um tipo de inserção mais assimilada, que neste momento se afigura apenas como uma tendência. Esta tendência na integração parece confirmada ainda, pela incipiente mobilização étnica e por um acolhimento tendencialmente não hostil da sociedade portuguesa.

Finalmente, importa dar conta da necessidade de introduzir nuances nesta análise, resultantes da introdução da variável contextual. De facto, mes- 
mo que entendamos que o caso da integração dos imigrantes em Peniche e em Lisboa se aproxima tendencialmente mais do modelo da assimilação, trata-se contudo de dois contextos diferenciados, tal como o são sempre as sociedades, ideia de que dá conta a noção de assimilação segmentada (Portes e Zhou, 1993 cit. por Pires, 2003). Assim, se no caso de Lisboa se poderia falar de uma situação de tendencial assimilação pela via institucional, em Peniche essa assimilação parece ser de tendência mais comunitária. Finalmente, no Alentejo a análise das formas de integração parece remeter justamente para a sua negação, a exclusão nos diferentes planos, o da sociedade de acolhimento e o do grupo de pertença, embora o papel de algumas organizações da sociedade civil tenda a atenuar esta tendência.

\section{Bibliografia}

ANTUNES, Maria José (2008) “A decisão de migrar. Portugal como destino da imigração da Europa de Leste na viragem do século", Cidades. Comunidades e Territórios, n. ${ }^{0}$ 15, Lisboa, CET-ISCTE, pp. 87-100.

MATOS, Madalena (coord.), AFONSO, J. Antunes, M. J. L., Castro, A e MARQUES, S. 2007 Entre o rural e o urbano: estratégias de integração de famílias de imigrantes da Europa de Leste, Relatório de Investigação, Centro de Estudos Territoriais e Fundação para a Ciência e a Tecnologia.

BAGANHA, Maria Ioannis, José Carlos Marques, Pedro Góis (2004), "Novas migrações, novos desafios: a imigração do Leste Europeu", Revista Crítica de Ciências Sociais n. ${ }^{\circ}$ 69, Outubro, pp. 95-115.

CASTRO, Alexandra (1999) O gosto na arquitectura popular. As casas dos emigrantes portugueses em França e em Portugal, Tese de Mestrado em Sociologia do Território, Lisboa, ISCTE.

CASTRO, Alexandra; MARQUES, Ana Sofia (2005) Tipificação das Situações de Exclusão em Portugal Continental, Lisboa, Instituto da Segurança Social, http://195.245.197.202/left. asp?03.06.10.02

COSTA, Paulo Manuel, 2004, Políticas da Imigração e as Novas Dinâmicas da Cidadania em Portugal, Lisboa, Instituto Piaget.

CUNHA, Isabel Ferin, Clara Almeida Santos (2006) Media, Imigração e Minorias Étnicas II, Colaboração de Catarina Valdigem e Willy S. Filho, Observatório da Imigração, 19, Alto Comissariado para a Imigração e Minorias Étnicas (ACIME).

DIONÍSIO, Sandra et al. (2005) Português língua não materna. Análise do inquérito no âmbito do conhecimento da situação escolar dos alunos cuja língua materna não é o português, Instituto de Estudos Sociais e Económicos e Direcção-Geral de Inovação e Desenvolvimento Curricular, disponível em http://www.dgidc. min-edu.pt/plnmaterna/RelatorioFinal.pdf

FERRÃO, João (2000) "Relações entre mundo rural e mundo urbano. Evolução histórica, situação actual e pistas para o futuro", Sociologia Problemas e Práticas, n. $^{\circ} 33$, Oeiras, Celta Editora.

FONSECA, Maria Lucinda et al. (2004) "Immigration to medium sized cities and rural areas: the case of eastern europeans in the Evora Region (southern Portugal)" in New Waves: migration from eastern to southern Europe, Lisboa, Fundação Luso-Americana, pp. 91-118.

GUERRA, Isabel (1991) Changements urbains et modes de vie dans la péninsule de Setúbal de 1974 a 1986, thèse pour le doctorat en sciences sociales appliquées au développement, Tours, Texto Policopiado.

HEISLER, Barbara Schmitter (1992)The Future of Immigrant Incorporation: Which Models? Which Concepts? Source: International Migration

INTERNATIONAL MIGRATION REVIEW, Vol. 26, No. 2, Special Issue: The New Europe and International Migration, pp. 623-645

JANVIE, Yves (1993) «L'intégration des villes et des campagnes» in Kaisses, B., Naissance des nouvelles campagnes, Paris, Ed. L'Aube.

LAGES, Mário (coordenação), Verónica Policarpo, José Carlos Marques, Paulo Lopes Matos e João Homem Cristo António (2006) Os Imigrantes e a População Portuguesa Imagens Recíprocas - Análise de duas sondagens, Observatório da Imigração, 21, Alto Comissariado para a Imigração e Minorias Etnicas (ACIME).

MACHADO, Fernando Luís (1999) Contrastes e Continuidades. Migração, Etnicidade e Integração dos Guineenses em Portugal, tese de doutoramento em Sociologia orientada pelo Professor Doutor João Ferreira de Almeida, Instituto de Ciências do Trabalho e da Empresa, policopiado.

MINGIONE, Enzo; PUGLIESE, Enrico (1987) “A difícil delimitação do urbano e do rural: alguns exemplos e implicações teóricas", Revista Crítica de Ciências Sociais, n. ${ }^{\circ}$ 22, Abril 1987.

PERISTA, Pedro (2005), "Imigrantes de Leste na Área Metropolitana de Lisboa. Novos Fluxos, Novos Perfis?", Cidades, Comunidades e Territórios, 9, 71-82, Lisboa, Centro de Estudos Territoriais, ISCTE.

PIRES, Rui Pena (2003), Migrações e Integração, Oeiras, Celta.

PIRES, Sónia (2004), "O Terceiro Sector Imigrante e as Associações dos Imigrantes do Leste Europeu em Portugal: Estruturação de um Novo Espaço de Cidadania?", Coimbra, CES, disponível em (http://www.ces.uc.pt/publicacoes/oficina/204/204.pdf (último acesso Agosto de 2007).

PORTES, Alejandro e ZHOU, Min (1993) "The new second generation: segmented assimilation and its variants among post, 1965 immigrant youth", Annals of the American Academy of Politics and Social Science, 530, pp. 47-98.

PORTES, Alejandro (1999) "A Sociologia económica e a sociologia da imigração. Panorâmica conceptual”, Migrações Internacionais. Origens, Tipos e Modos de Incorporação, Oeiras, Celta Editora, pp. 5-40. 
SABINO, Catarina (2006) "As mulheres imigrantes na imprensa portuguesa", In PEIXOTO, João (coord.) CASACA, S. F.; FIGUEIREDO, A.; GONÇALVES, M.; FLORIANO, A.; SABINO, C.; LOPES, M.C.; PERISTA, H.; PERISTA, P.; PHIZACKLEA, A., Mulheres Migrantes. Percursos Laborais e Modos de Inserção Socioeconómica das Imigrantes em Portugal, Relatório Final (versão síntese), Socius, ISEG/UTL; CESIS, University of Warwick, Lisboa, 2006.

REIS, José (2001) "Observar a mudança: o papel dos Estudos Rurais", Oficina do CES, Novembro 2001. http://www.ces.fe.uc. pt/publicacoes/oficina/165/165.php
Rede Social do Concelho de Peniche (2004), Diagnóstico Social.

REMY, Jean et al. (1998) La ville, vers une nouvelle definition?, Paris, L'Harmattan.

ROSA, Maria João Valente (2005) (Des)encontro entre as Migrações Internacionais (laborais) e as Qualificações (escolares): o caso dos europeus de Leste em Portugal, Socinova.

ZHOU, Min (1997) "Segmented assimilation: issues, controversies, and recent research on the second generation", International Migration Review, 31 (4), pp. 975-1008. 